\title{
Recurrence of Hepatic Hydatidosis: How and Why?
}

\author{
Ismail Alper Tarim $^{1(\mathbb{D})}$, Vahit Mutlu ${ }^{2(\mathbb{D})}$, Kagan Karabulut ${ }^{1(\mathbb{D})}$, Recep Bircan ${ }^{1(\mathbb{D})}$, \\ Murat Derebey ${ }^{1(\mathbb{D})}$, Ayfer Kamalı Polat ${ }^{1(\mathbb{D})}$, Kenan Erzurumlu ${ }^{1(\mathbb{D})}$ \\ ${ }^{1}$ Department of General Surgery, Ondokuz Mayis University Medical Faculty, Samsun, Turkey. \\ ${ }^{2}$ Department of General Surgery, Tokat State Hospital, Tokat, Turkey.
}

Copyright@ Author(s) - Available online at https://dergipark.org.tr/en/pub/mbsjohs Content of this journal is licensed under a Creative Commons Attribution-NonCommercial 4.0 International License,

Received: 04 April 2021, Accepted: 10 August 2021, Published online: 31 August 2021

(C) Ordu University Institute of Health Sciences, Turkey, 2021

\begin{abstract}
Objective: For recurrence of hepatic hydatid, cysts overlooked during surgery, secondary cysts due to the spread of cystic fluid, late postoperative hydatid cyst formation and inadequate treatment are recommended. Factors affecting recurrence were investigated in cases with recurrence. In this retrospective study, data on 199 patients with hepatic hydatid disease treated by surgery in our hospital, between January 1993 and December 2018 were reviewed.

Methods: In this study, patients who were operated for hepatic hydatid disease; The relationship between cyst diameters, cyst stages, number of cysts and recurrence was investigated.

Results: 84 patients were male and 115 were female. Most of the cases (189 patients- $88.06 \%$ ) treated by conservative surgical methods. Remaining's (8 patients-4.3\%) had total cystectomy or segmental hepatectomy. Recurrence rate was found $5.47 \%$. In that cases, primary operations were done by us, there was no significant differences between cysts' stages and recurrences. There was not significantly differences between cysts' number and recurrences, except the patients had 2 cysts $(\mathrm{z}=2.17, \mathrm{p}=0.03)$.

Conclusion: The best way of prevention of the recurrence of hepatic hydatid cysts are complete diagnosis of cysts' classification, localization, and medico-surgical combination. Perioperative medical treatment must be start three days ago before the operation and should be continued for at least 6 months.
\end{abstract}

Key words: Hepatic Hydatidosis, Recurrence, Overlooked cysts

Suggested Citation: Tarim I A, Mutlu V, Kağan Karabulut, Bircan R, Derebey M, Polat A K, Erzurumlu K. Recurrence of Hepatic Hydatidosis: How and Why?..Mid Blac Sea Journal of Health Sci, 2021; 7(2):186-191

\section{Address for correspondence/reprints:}

Ismail Alper Tarim

Telephone number: (+90) 5306335390

E-mail: ismailalpert@gmail.com 


\section{Introduction}

Hydatid cyst causes infection in the liver with the ingestion of parasite eggs, which are thrown into the external environment by the host, by human digestion $(1,2)$. Hepatic hydatid, which is diagnosed serologically and radiologically, is usually treated with surgical methods (3). Recurrence may occur despite surgical treatment. Recurrence may have many reasons such as insufficient drainage, overlooked cysts, spread into the abdomen during surgery, and lack of medical treatment. Even postoperative cystic cavity collections may cause false recurrence diagnosis (4-7).

Recurrence of hepatic hydatid cysts is the most common and serious complication of hydatid surgery. Although perioperative or single albendazole treatment is effective as high as 77-97 \% and better results with praziquantel combination, it still remains controversial (8-10).

On the other hand, enlargements of hepatic hydatid cysts are not clear. In most of reports that growth rate has recommended 1-2.5 mm per month (10-12). Also, some authors have reported enlargement $4-5 \mathrm{~cm}$ per year. Also, it has been reported that cystic growth one centimeter in diameter during the first six months and then it is strictly related to host immunity and the surrounding tissue resistance (13). Roaming has reported that about 30 $\%, 45 \%$ and $11 \%$ of cyst grew about $1-5 \mathrm{~mm}, 6-15$ $\mathrm{mm}$ and mean $31 \mathrm{~mm}$ per year respectively. The cysts and the sizes did not change or got lesser in $16 \%$ (14). Our aim in this report was to investigate the factors affecting recurrence in hepatic hydatidosis.

\section{Methods}

In this retrospective study, data on 199 patients with hepatic hydatid disease treated by surgery and dual benzoimidazole derivate treatment in Ondokuz Mayis University Medical Faculty Department of General Surgery, between January 1993 and December 2018 were reviewed.

\section{Patients}

All the records were evaluated retrospectively. The histories of the cases were investigated as preoperative hydatid procedures and recurrences.

Diagnoses were done by ultrasonography (US), computed tomography (CT) and/or magnetic resonance investigation (MRI). Also, serological analyses (including IHA and/or echinococcosis Ig G) were done. Since 1996, intraoperative ultrasonography (IOUS) was used routinely for the diagnosis of probably "overlooked cysts" (15).

\section{Medical treatment protocol}

Perioperative benzoimidazole therapy was started immediately and continued in postoperative period for 6-12 months as monthly cure application. Because of no albendazole drug for human was in sale in that time in Turkey, the former 11 cases $(5.53 \%)$ had mebendazole $(50 \mathrm{mg} / \mathrm{kg} / \mathrm{d})$ therapy. By the time, albendazole $(10-12 \mathrm{mg} / \mathrm{kg} / \mathrm{d})$ used in the laters $(188$ cases, $94.47 \%$ ).

In operation, benzoimidazole solutions in concentration of $2 \% \mathrm{mgr}$, were used for cystic cavity disinfection, have been reported previously $(9,16-18)$.

\section{Surgical procedure}

All the cysts were treated by surgically. In 189 cases $(94.97 \%)$ conservative procedures such as drainage, evacuation, omentoplasty were the method of choice. The remainings (10 cases-5.03\%) were treated by total cystectomy with or without hepatectomy.

\section{Postoperative follow-up}

The patients were evaluated by serological tests and either US and/or CT-scan on the fifth to seventh day and at the first, sixth and twelfth months in the post-operative period. Patients were evaluated on an annual basis by US after the first year of follow-up.

If suspected lesions were found in US and/or radiological imaging, percutaneous transhepatic cystic liquid sampling was done. Then, protoscolices were examined by light microscopy. If protoscolices were seen, it was recommended recurrence. So, it was determined as golden rule: "no protoscolices no recurrence"

\section{Evaluations of recurrences}

The recurrences were evaluated as four forms as "overlooked cyst", "insufficient/incomplete drainage of cystic cavity", "secondary hydatidosis" and "reinfestation"; depending on diagnostic times, cysts' sizes and natural cyst growth in human livers (1-2.5 cm per year)_(Table 1) $(15,19,20)$.

\section{Statistical analysis}

Statistical analysis was done by using " $\mathrm{Z}$ Test for proportion" on pc.

\section{Results}

84 patients were male and 115 were female. Mean age was $47.74 \pm 16.463$ years (range 18 -84 years). Most of the patients (115 cases, $57.79 \%$ ) had one cyst. The others had two or more cysts. Most of the cases (189 patients $-88.06 \%$ ) treated by conservative surgical methods. (Either cystic evacuation with or 
without omentoplasty or capittonage). Remaining's (8 patients $-4.3 \%$ ) had total cystectomy or segmental hepatectomy.

Nineteen recurrences $(9.45 \%)$ were found in whole patients in $12^{\text {th }}-360^{\text {th }}$ postoperative months. But only eleven of these cases $(5.47 \%)$ have been operated by our team. The mean recurrence time was $72.55 \pm 57.327$ months (range 12-192 months). So, totally 20 recurrences $(10.05 \%)$ were investigated. Diagnosis of recurrences established in $12^{\text {th }}-360^{\text {th }}$ postoperative months.

Only eleven cases of recurrences $(5.47 \%)$ had been operated by our team. All of them had been treated by conservative surgery. In those cases, the mean recurrence time was $72.55 \pm 57.327$ months (range 12-192 months). The remaining's (9 cases $4.52 \%$ ) have been treated at other hospitals. Eight of them had treated by surgical procedures and one had been percutaneously drainage. The mean recurrence time was $144.5 \pm 145.334$ months (range 16-360 months).

So, recurrence rate of our study was found $5.47 \%$. According to table 1, three of them were reinfestations. The intervals of recurrences were $154 \pm 36.166$ months (range 120-192 months). Eight cases were probably overlooked cysts (mean time was $42 \pm 20.284$ months, range 12-60 months). In that cases, primary operations were done by us, there was no significant differences between cysts' stages and recurrences (Table 2). On the other hand, there was not significantly differences between cysts' number and recurrences, except the patients had 2 cysts $(\mathrm{z}=2.17, \mathrm{p}=0.03)$ (Table 3 ).

Table 2. Recurrence rates according to cysts' stages. ( $Z$ Test for proportion)

\begin{tabular}{llclcc}
\hline Stage & \multicolumn{2}{c}{$\mathrm{n}$} & \multicolumn{2}{c}{$\mathrm{Z}-\mathrm{p}$} \\
& Whole cases & Recurrences & $\%$ & $\mathrm{z}$ & $\mathrm{p}$ \\
\hline I & 38 & 3 & 7.89 & -0.64 & 0.520 \\
II & 71 & 3 & 4.23 & 0.17 & 0.869 \\
III & 76 & 2 & 2.63 & 0.89 & 0.372 \\
IV & 48 & 3 & 6.25 & -0.42 & 0.676 \\
V & - & - & - & & \\
\hline
\end{tabular}

Table 3. Recurrence rates according to cysts' number (Z Test for proportion)

\begin{tabular}{llclll}
\hline $\begin{array}{l}\text { Number } \\
\text { of Cysts }\end{array}$ & Whole cases & $\mathrm{n}$ & \multicolumn{3}{c}{$\mathrm{z}-\mathrm{p}$} \\
\hline 1 & 138 & 13 & 9.42 & -0.08 & 0.933 \\
2 & 43 & 1 & 2.33 & 2.17 & 0.030 \\
3 & 7 & 1 & 14.29 & -0.31 & 0.765 \\
4 & 5 & 2 & 40 & -1.41 & 0.158 \\
$\geq 5$ & 6 & 1 & 16.67 & -0.74 & 0.461 \\
\hline
\end{tabular}

Table 1. Causes of hepatic hydatidosis recurrence.

\begin{tabular}{|c|c|c|c|}
\hline & Cyst's diameter & Time of diagnosis after & Localisation \\
\hline & & operation & \\
\hline Overlooked cyst & $>1-2.5 \mathrm{~cm}$ p.y. & $\begin{array}{l}\text { Close (Commonly in first } \\
\text { postoperative year) }\end{array}$ & Liver \\
\hline $\begin{array}{l}\text { Insufficient drainage of } \\
\text { cystic cavity }\end{array}$ & $\begin{array}{l}\text { Similar with } \\
\text { preoperative diameter }\end{array}$ & $\begin{array}{l}\text { Commonly second } \\
\text { postoperative years }\end{array}$ & Liver \\
\hline Secondary hydatidosis & $1-2.5 \mathrm{~cm}$ p.y. & Commonly in 3 years & $\begin{array}{l}\text { Extrahepatic peritoneal } \\
\text { cavity }\end{array}$ \\
\hline$\underline{\text { Re-infestation }}$ & $<1-2.5 \mathrm{~cm}$ p.y. & $\begin{array}{l}\text { Commonly } 5 \text { years or more } \\
\text { after surgical treatment }\end{array}$ & $\begin{array}{l}\text { Anywhere in whole body } \\
\text { (Also liver) }\end{array}$ \\
\hline
\end{tabular}

All of these patients were treated by conservative surgery and has got off follow-up and albendazole treatment started at least perioperative 4 days preoperatively and in second postoperative days for 6 months in cyclic form.

In early stages of this study, 2 cases $(1.08 \%)$ "overlooked cysts" were found at post-operative $3^{\text {rd }}$ and $5^{\text {th }}$ days and treated by PAIR. After those cases, IOUS was used. In those cases, four centrally localised hydatid cysts of high risk of vasculary and ductal injuries were determined. So, they were treated by puncture and injection of albendazole solution.

There were 2 deaths $(0.99 \%)$ due to hydatidosis. A 71-year-old female patient has died due to cardiopulmonary insufficiency (died on $18^{\text {th }}$ hours after hepatic hydatid surgery). Another male patient aged 74 years old has died on second month because of "brain hydatid cyst".

In late postoperative period, there were 22 $(10.95 \%)$ deaths unrelated to hydatid diseases). One hundred seventy-seven patients were followed up for 24-297 months (164.62 \pm 79.108$)$. 


\section{Discussion}

As a term of "recurrence" means, "the return of a sign, symptom or disease after a remission. If a treated infectious/parasitic disease re-occurs after long time symptom-free interval, it may be result of reinfection or re-infestation. It is necessary that new terminology must explain whether infection due to relapse in deficiently treated/non symptomatic patients or just new one.

"Recurrence" of hydatid cysts of the liver is one of the most serious complications in surgery. This pathology which is generally investigated under the title of recurrence may be arranged in four different titles as true recurrence, secondary hydatidosis, insufficiency of drainage or evacuation and overlooked cysts. On the other hand, in post-operative period, cystic cavity collections commonly imitate recurrence, cause false diagnosis.

Recurrence rates in the literature vary with the time of the study and treatment methods. Eventually, the recurrence rates in the literature are between 1.1 and 24\% (19-25). Some of the recurrence rates are unacceptably high. However, cases accepted as recurrence have different characteristics.

Reports on the development of hepatic hydatidosis makes the recurrence problem controversial. That is: the cyst diameter grows $\geq 1 \mathrm{~mm}$ monthly. Therefore, the growth of the cyst diameter in one year is about 1$2.5 \mathrm{~cm}$. Is it true to refer one or more small cysts located centrally in the liver may be found in shorter postoperative period than expecting developing time? It is hard to talk "recurrence". It must be considered an "overlooked" or "missed" liver hydatid cyst $(15,20)$.

Recurrence rates, change with the performance of medical treatment, the type of surgical treatment and the experience of the surgeon. It is not possible to say that complications of surgical treatment are completely prevented (25-27). Medical treatment applied by surgical methods to prevent or minimize dissemination, may be effective in preventing recurrence.

Of course, in the cases of multiple hydatid and/or satellite cysts risk of overlooked cyst arises. So, IOUS is very helpful (15). But the benefit of IOUS is not absolutely. The quality of ultrasonic equipment and experience of staff will effect the results. If a cyst is lesser then $1 \mathrm{~cm}$ diameter it may be undetected easily.

The main reasons for overlooked cases are the presence of multiple cysts, satellite cysts, centrally localized non-palpable, of lesser diameter cysts. In spite of preoperative assessment by US, CT, and MRI, overlooked cysts continue to be problems in surgery. So, IOUS must be used especially in the case of multiple cysts, routinely.

In literature, it is clearly shown that, radical surgical procedures are with lower recurrence rates than conservative surgery $(27,28)$; but never explained "why". In conservative methods such as "evacuation with or without omentoplasty", "capittonage", "drainage", recurrences can be explained by "overlooking", "satellite cysts", "incompetent evacuation-sterilization of communicated cysts", "spreading" or "re-infestation". But these are not enough, in the cases of treated by radical surgery such as "totally cystectomy, "anatomical" or "non anatomical hepatectomy" with "no cystic perforation and/or spreading of cystic liquid". So, the causes of recurrences still remain controversial $(24,26,27)$.

"On the other hand, comparing the treatment results (also morbidity-mortality and recurrence rates) of different patient groups from the same center leads to false results. Patients presenting to any center are grouped according to disease and personal characteristics and different treatment methods are applied. How realistic is it to compare the results of surgical methods? Can the results of percutaneous drainage be the same in early and late-stage cysts? Can the results of video laparoscopic treatment in posteriorly localized or multicystic lesions be as good as applicable cases? Is it correct to compare the results of cases performed by selecting convenient cases for radical interventions and inconvenient cases in which conservative treatment was applied?" (20).

It is necessary that:

a. All cysts found in the patients should be identified pre-and intraoperatively.

b. Being aware of, in $30 \%$ of liver hydatid cysts, there is more than one cyst. Satellite and multiple and closed location cysts.

c. In the early postoperative period, the operation site and the liver should be definitely investigated by CT or MRI for overlooked cysts and/or cystic cavity collections.

d. Prevention of cystic liquid or spreading vesicles into the peritoneal cavity. It is the cause of "secondary hydatidosis".

About hepatic hydatid cyst recurrences, there are some questions need discussion:

1. How to establish diagnosis of recurrence?

Cystic cavity collections and/or infections are eliminated. So, if US, CT, MRI investigations suggest of doubt, percutaneous transhepatic sampling and investigation of protoscolices must be done.

\section{Effectiveness of medical treatment:}


The success rate of albendazole treatment alone is about $77-97 \%$. Currently, peri-operative medical treatment decreases the recurrence rate. It is reported that, preoperative albendazole treatment for at least 34 days is sufficient for sterilization of the cyst content. Current reports are shown that albendazolepraziquantele combination is more effective than albendazole is alone. In this study, perioperative medical treatment was used when the diagnosis is done.

The cysts' stage and number are not clearly shown that effectiveness on recurrences. In this study, the cases had two cysts were found lesser recurrence rate than had one. It is thought that the cases of two or more cysts -especially lesser than $1 \mathrm{~cm}$ diameterdiagnosed had single cyst. So overlooked cysts, detected as of single cyst. Those cases had overlooked cysts and recommended as recurrence.

On the other hand, the cases of recurrences who had primary operations at other clinics are not included and evaluated in this study.

\section{Conclusion}

1. The best way of prevention of hepatic hydatid cysts recurrences are complete diagnosis of cysts' clasification, localisation and medico-surgical combination.

2. Serological tests are valuable in diagnosis but because of false positivity, never in follow-up.

3. Perioperative medical treatment must be done and start 3 days ago before the operation at least.

4. Medical treatment must be continued 6 months, at least.

5. Cystic cavity collections are more common than reported. If seen, percutaneous aspiration and search of protoscolices must be done absolutely.

Ethics Committee Approval: This study was conducted with approval from our hospital's ethics committee (approval number: 2020/651; approval date: January 26.11.2021).

Peer-review: Externally peer-reviewed.

\section{Author Contributions:}

Author Contributions: Concept: I.A.T, KE; Design: I.A.T, KE; Literature Search: I.A.T, KE Data Collection and Processing: V.M, M.D, K K, R. B, A.K.P; Analysis or Interpretation: V.M, M.D, K K, R. B, A.K.P; Writing: V.M, M.D, K K, R. B, A.K.P;

Conflict of Interest: No conflict of interest was declared by the authors.

Financial Disclosure: The authors declared that this study hasn't received no financial support.

\section{References}

1. Karaman U, Miman O, Kara M, Gicik Y, Aycan OM, Atambay M. Hydatid cyst prevalence in the region of Kars. Turkey parasitology journal. 2005;29(4):238-40.

2. Karaman U, Daldal N, Atambay M, Aycan OM. Serological Results of Cases with A Presumptive Diagnosis of Hydatid Cyst During 1999-2002 In The Inonu University Medical Faculty. Journal of Turgut Ozal Medical Center. 2002;9(4):233-5.

3. Dogan K, Kaya C, Karaman U, Kalayci MU, Baytekin, HF. Tuboovarian abscess caused by hydatid cyst: a rare case. Microbiology bulletin. 2013;47(2):356-61.

4. Jaén-Torrejimeno I, López-Guerra D, PradaVillaverde A, Blanco-Fernández G. Pattern of Relapse in Hepatic Hydatidosis: Analysis of 238 Cases in a Single Hospital. J Gastrointest Surg. 2020;24(2):361-7.

5. Pang Q, Jin H, Man Z, Wang Y, Yang S, Li Z, et al. Radical versus conservative surgical treatment of liver hydatid cysts: a meta-analysis. Front Med. 2018;2(3):350-9.

6. Goja S, Saha SK, Yadav SK, Tiwari A, Soin AS. Surgical approaches to hepatic hydatidosis ranging from partial cystectomy to liver transplantation. Ann Hepatobiliary Pancreat Surg. 2018;22(3):208-15.

7. Wu K, Feng X, Liu X, Wang W. Residual cavity hydrops initially misdiagnosed as recurrent hepatic echinococcosis. Lancet Infect Dis. 2019;19(5):557.

8. Saimot AG, Meulemans A, Cremieux AC, Giovanangeli MD, Hay JM, Delaitre B, et al. Albendazole as a potential treatment for human hydatidosis. Lancet 1983;ii:652-6.

9. Polat C, Dervisoglu A, Hokelek M, Yetim I, Buyukkarabacak Y, Ozkutuk Y, et al. Dual treatment of albendazole in hepatic hydatidosis: A new therapeutic modality of 52 cases. J Gastroenterol Hepatol 2005;20(3):421-5.

10.Puliga A, Sulis R, Pala M, Sechi R, Pietrangeli M. Surgical treatment of hydatid liver cysts: 20 more years of experience. Chir Ital. 2003;55:533-40.

11. Morris DL. Pre-operative albendazole therapy for hydatid cyst. Br J Surg. 1987;74:805-6.

12.Altıntas N, Tınar R, Çoker A. Cystic and alveolar echinococcosis pathogenesis. Hydatidology Society Publications. 2004;1:149-58.

13. Von Lichtenberg F. Pathology of infectious diseases. New York: Raven Press. 1991:331-5.

14.Koksal AS, Arhan M, Oguz D. Hydatid cyst, Current Gastroenterology, 2004;8(1):61-67. 
15.Dervisoglu A, Erzurumlu K, Tac K, Arslan A, Gürsel M, Hökelek M. Should intraoperative ultrasonography be used routinely in hepatic hydatidosis? Hepato-Gastroenterology. 2002;49(47):1326-8.

16.Erzurumlu K, Ozdemir M, Mihmanlı M, Cevikbas $\mathrm{U}$. The effect of intraoperative mebendazolealbendazole aplications on hepatobiliary system. Eur Surg Res. 1995;27:340-5.

17. Karabulut K, Ozbalci, GS, Kesicioglu T, Tarim IA, Lap G, Kamali Polat A, et al. Long-term outcomes of intraoperative and perioperative albendazole treatment in hepatic hydatidosis: single center experience. Annals of Surgical Treatment and Research. 2014;87(2):61-65.

18. Yetim I, Erzurumlu K, Hokelek M, Baris S, Dervisoglu A, Polat C, et al. The results of alcohol and albendazole injections in hepatic hydatidosis (An experimental study) J Gastroenterol Hepatol. 2005;20(9):1442-7.

19. Velasco-Tirado V, Romero-Alegría Á, BelhassenGarcía M, Alonso-Sardón M, Esteban-Velasco C, López-Bernús A, et al. Recurrence of cystic echinococcosis in an endemic area: a retrospective study. BMC Infect Dis. 2017;17(1):455.

20.Erzurumlu K. Complications of Hydatid Surgery", In "Human Echinococcosis", Ed. by Erzurumlu K. Ch VIII, European Medicine Bookselling, 2011;95-98.

21.Demircan O, Baymus M, Seydaoglu G, Akinoglu A, Sakman G. Occult cystobiliary communication presenting as postoperative biliary leakage after hydatid liver surgery: Are there significant preoperative clinical predictors? Can J Surg. 2006;49:177-84.

22.Sherman S, Ruffolo TA, Hawes RH, Lehman GA. Complications of endoscopic sphincterotomy: A prospective series with emphasis on the increased risk associated with sphincter of Oddi dysfunction and nondilated bile ducts. Gastroenterology. 1991;101:1068-75.

23.Tekin A, Kücükkartallar T, Kartal A, Kaynak A, Ozer S, Tavli S, et al. Clinical and surgical profile and follow up of patients with liver hydatid cyst from an endemic region. J Gastrointestin Liver Dis. 2008;17:33-7.

24. Salm LA, Lachenmayer A, Perrodin SF, Candinas D, Beldi G. Surgical treatment strategies for hepatic alveolar echinococcosis. Food Waterborne Parasitol. 2019;5:15-50.
25. Yagci G, Ustunsoz B, Kaymakcioglu N, Bozlar U, Gorgulu S, Simsek A, et al. Results of surgical, laparoscopic, and percutaneous treatment for hydatid disease of the liver: 10 years experience with 355 patients. World J Surg. 2005;29:1670-9.

26.Bülbüller N, İlhan YS, Kirkil C, Yeniçerioğlu A, Ayten R, Cetinkaya Z. The results of surgical treatment for hepatic hydatid cysts in an endemic area. Turk J Gastroenterol. 2006;17:273-8.

27.De Werra C, Condurro S, Tramontano S, Perone M, Donzelli I, Di Lauro S, et al. Hydatid disease of the liver: thirty years of surgical experience. Chir Ital. 2007;59:611-25.

28.Fancellu A, Perra T, Vergari D, Vargiu I, Feo CF, Cossu ML, et al. Management of complex liver cystic hydatidosis: challenging benign diseases for the hepatic surgeon: A case series report from an endemic area. Medicine (Baltimore). 2020;99(48):234-35. 